\title{
Policy on Dissemination of Federal Information Resources Updated
}

\author{
Michael Brintnall, $A P S A$
}

In an age of both intense costcutting and technological advance, federal information policy is in transition. There is in particular growing pressure to institute or increase fees for federal data, and to substitute electronic forms of information for hard copies.

In mid-summer the OMB issued the first of two notices setting future government information policy. Revised Circular A-130, entitled "Management of Federal Information Resources," was issued in late June. The purpose of the circular is to establish federal policy for agencies to follow when acquiring, using, and distributing government information. The main thrust of the revisions in this policy are to encourage government agencies to use new technologies to improve public access to government information, such as CD-ROM, computer tape, and online services. It urges that electronic information also be disseminated to depository libraries, which have traditionally received hard copy. The Government Printing Office distributes materials to depository libraries; the new policy consequently calls for new roles for GPO and new linkages between agencies supplying data in electronic form and the GPO.

The circular also covers policy for data costs, advising that agencies charge only costs associated with dissemination of information, and not base charges on the costs of data collection or analysis. Agencies are also to cooperate in the establishment of a centralized government information locator system.

Policy statements on the management of government information resources have not been released, and are being considered in the context of the administration's work to "reinvent"' government.

One area in which the move toward electronic dissemination of information is having an immediate effect is the publications of the Foreign Broadcast Information Service (FBIS) and the Joint Publications Research Service (JPRS) which are compilations of documents worldwide, assembled by the CIA, and relied on by many scholars to track world affairs. The National Technical Information Service (NTIS), which distributes these documents to scholars, plans in the near future to have a CD-ROM version of them out, distributed quarterly (with the intent to move to monthly distribution).

Much of the information in FBIS and JPRS is copyrighted information incurring royalty charges. The U.S. has adopted the Berne Convention which extends copyright protection to foreign works. The CIA is concerned about this financial burden, and NTIS says the pricing of a CD-ROM edition will likely reflect these costs (though such charges might be construed as passing on data collection costs rather than data dissemination and run afoul of A-130). For the foreseeable future NTIS is committed to providing hard copy versions as well, probably in the form of microfiche, as will the GPO provide hard copy to depository libraries.

Electronic dissemination raises questions about electronic access, and particularly about whether some scholars will lack resources or technology to make use of it. APSA, advised by its Departmental Services and Publications Committees, is tracking access to electronic resources now, and will continue to monitor these issues closely.

The revised OMB Circular A-130 is printed in the Federal Register, July 2, 1993, pp. 36068-86; and is available from the OMB Publications Office at (202) 395-7332. APSA will continue to follow the emergence of new federal information policy, relying in particular on the work of the Consortium of Social Science Associations (COSSA) and the Council of Professional Associations on Federal Statistics (COPAFS), of which APSA is a member. Anyone with questions is invited to contact Michael Brintnall at APSA, (202) 483-2512, or bitnet: incem024@sivm. 